\title{
QUEEN'S
UNIVERSITY
BELFAST
}

\section{CSF Beta-amyloid 1-42 Concentration Predicts Delirium Following Elective Arthroplasty Surgery in an Observational Cohort Study}

Cunningham, E. L., McGuinness, B., McAuley, D. F., Toombs, J., Mawhinney, T., O'Brien, S., Beverland, D., Schott, J. M., Lunn, M. P., Zetterberg, H., \& Passmore, A. P. (2018). CSF Beta-amyloid 1-42 Concentration Predicts Delirium Following Elective Arthroplasty Surgery in an Observational Cohort Study. Annals of Surgery. https://doi.org/10.1097/SLA.0000000000002684

Published in:

Annals of Surgery

Document Version:

Peer reviewed version

Queen's University Belfast - Research Portal:

Link to publication record in Queen's University Belfast Research Portal

\footnotetext{
General rights

Copyright for the publications made accessible via the Queen's University Belfast Research Portal is retained by the author(s) and / or other copyright owners and it is a condition of accessing these publications that users recognise and abide by the legal requirements associated with these rights.
}

Take down policy

The Research Portal is Queen's institutional repository that provides access to Queen's research output. Every effort has been made to ensure that content in the Research Portal does not infringe any person's rights, or applicable UK laws. If you discover content in the Research Portal that you believe breaches copyright or violates any law, please contact openaccess@qub.ac.uk. 
CSF beta-amyloid 1-42 concentration predicts delirium following elective arthroplasty surgery in an observational cohort study

\section{Authors:}

Emma L Cunningham, PhD, Centre for Public Health, Queen's University Belfast

Bernadette McGuinness, PhD, Centre for Public Health, Queen's University Belfast

Daniel F McAuley, MD, Centre for Experimental Medicine, Queen's University Belfast

Jamie Toombs, MSc, Department of Molecular Neuroscience, University College London, Institute of Neurology

Tim Mawhinney, BSc, Primary Joint Outcomes Unit, Musgrave Park Hospital, Belfast Trust Seamus O’Brien, PhD, Primary Joint Outcomes Unit, Musgrave Park Hospital, Belfast Trust David Beverland, MD, Primary Joint Outcomes Unit, Musgrave Park Hospital, Belfast Trust Jonathan M Schott, MD, Dementia Research Centre, University College London, Institute of Neurology

Michael P Lunn, PhD, Dementia Research Centre, University College London, Institute of Neurology Henrik Zetterberg, PhD, Department of Molecular Neuroscience, University College London, Institute of Neurology; Department of Psychiatry and Neurochemistry, the Sahlgrenska Academy at the University of Gothenburg, Mölndal, Sweden; Clinical Neurochemistry Laboratory, Sahlgrenska University Hospital, Mölndal, Sweden

Anthony P Passmore, MD, Centre for Public Health, Queen's University Belfast 
Corresponding Author (and contact for reprint requests): Dr Emma Cunningham

Address: Centre for Public Health, Queen's University Belfast, Block B Institute of Clinical Sciences, RVH site, Grosvenor Road, Belfast, BT12 6BA

Telephone: + 44 (0) 7815796863

Email: ecunningham03@qub.ac.uk; emmacunningham@doctors.net.uk

\section{Conflicts of Interest and Funding sources:}

This work was funded by the Siew Keok Chin Scholarship, the Belfast Arthroplasty Research Trust and Belfast Trust Charitable Funds.

Dr Emma Cunningham has received small grant funding from Alzheimer's Research UK. Professor Danny McAuley has received grant funding from the NIHR RfPB programme for delirium research. MPL received partial salary support from the Department of Health's National Institute for Health Research Biomedical Research Centres funding scheme. JMS acknowledges the support of the NIHR Queen Square Dementia BRU, the NIHR UCL/H Biomedical Research Centre, Wolfson Foundation, EPSRC (EP/J020990/1), MRC (CSUB19166), ARUK (ARUK-Network 2012-6-ICE; ARUK-PG2014-1946), Brain Research Trust ((UCC14191) and European Union's Horizon 2020 research and innovation programme (Grant 666992). For the remaining authors none were declared.

Short running head: CSF A $\beta$ predicts postoperative delirium 


\section{Mini-Abstract}

This observational cohort study of participants undergoing elective arthroplasty found an independent association between a cerebrospinal fluid biomarker of Alzheimer's Disease and subsequent delirium following surgery. This suggests that postoperative delirium may indicate incipient Alzheimer's disease and if replicated should influence postoperative follow-up practices.

\section{Abstract}

Objective: To test the hypothesis that $A P O E \varepsilon 4$ status and cerebrospinal fluid (CSF) A $\beta 42, \mathrm{~T}$-tau and P-tau would independently predict the risk of postoperative delirium.

Summary Background Data: Delirium following surgery is common and associated with adverse outcomes. Age and cognitive impairment are consistent risk factors for postoperative delirium.

Methods: This observational cohort study recruited 282 participants aged 65 years or older, without a diagnosis of dementia, admitted for primary elective hip or knee arthroplasty. Cognitive tests were undertaken preoperatively, blood and CSF were sampled at the time of spinal anaesthesia and participants were assessed daily postoperatively for delirium.

Results: Increasing age $(p=0.04)$, preoperative comorbidity $(p=0.03)$, type of surgery $(p=0.05)$, intravenous opioid usage $(p=0.04)$ and low CSF A $\beta 42(p<0.01)$ were independent predictors of postoperative delirium.

Conclusions: This study is the first to show an independent association between CSF A $\beta 42$ and delirium incidence in an elective surgical population, suggesting that postoperative delirium may indicate incipient Alzheimer's disease. 


\section{Introduction}

Delirium is common following elective arthroplasty surgery, with an estimated incidence of $17 \%(1)$, and is associated with significant negative outcomes including dementia and institutionalisation (2). As greater numbers of older people, with higher levels of comorbidity, undergo surgery (3), numbers developing postoperative delirium are likely to rise.

Whilst age and pre-existent cognitive impairment are established risk factors for postoperative delirium $(4,5)$ there is currently no reliable method to predict preoperatively who will become delirious after surgery. Better prediction would inform our understanding of the pathophysiological basis for delirium which remains unclear. In time it may also inform consent and perioperative counselling processes as well as care and discharge planning.

Given the consistent association between cognitive impairment and postoperative delirium, risk factors for, and biomarkers of, Alzheimer's disease (AD) are being investigated as predictors of postoperative delirium. The apolipoprotein $(A P O E) \varepsilon 4$ allele, the main genetic risk factor for $A D$, has been studied as a potential predictor of postoperative delirium with conflicting results (6-8).

Cerebrospinal fluid (CSF) amyloid $\beta 42$ (A $\beta 42)$, total tau (T-tau) and phospho-tau (P-tau) are established as biomarkers of the AD process, reflecting plaque pathology, neurodegeneration and neurofibrillary tangle pathology, respectively. Alterations in these biomarkers are seen prior to the clinical emergence of AD dementia (9). One study and one pilot study have suggested these biomarkers may be predictors of delirium in elective surgical populations $(10,11)$. Two other studies conducted in hip fracture populations yielded conflicting results $(12,13)$. A proven association between delirium and AD pathophysiology would necessitate review of follow-up practices. Although delirium is associated with subsequent cognitive decline no clinical standards regarding follow-up are in place in the UK and Ireland at the current time. 
This observational cohort study was designed to test the hypothesis that quantification of brain vulnerability, using $A P O E \& 4$ status and CSF A $\beta 42, \mathrm{~T}$-tau and P-tau would independently predict the risk of delirium following elective primary hip and knee arthroplasty in an older population.

\section{Methods}

\section{Study population}

Participants aged 65 years or older admitted for primary elective hip or knee arthroplasty to a single surgical centre and planned to undergo spinal anaesthesia with intrathecal diamorphine were eligible for inclusion. Other anaesthetic variations beyond this requirement were permitted. Exclusion criteria included a pre-existing diagnosis of dementia or other neurodegenerative condition, visual or hearing impairment such that the participant was unable to undertake the neuropsychological assessments, illiteracy and stroke with residual deficit.

Those participants for whom sufficient CSF was available for analyses were included in this study.

\section{Study methods}

Written informed consent was obtained from all participants and the study was performed in accordance with local ethical committee procedures (REC reference: 10/NIR01/5; protocol number: 09069PP-OPMS). Demographic data and potential confounding variables, as considered in similar previous studies $(10,12,13)$ (including age, gender, type of surgery, American Society of Anaesthesiologists physical (ASA) status (14), Charlson Comorbidity Index(CCI) (15), level of education, estimated IQ (16), functional status (17), depression score (18), smoking status and alcohol intake) were collected and included in analyses. Information regarding potential confounding operative and anaesthetic factors including surgical duration, intraoperative blood loss and hypotension and use of sedatives, opioids and general anaesthesia (19-21) was recorded from the medical charts where possible. Bispectral index monitoring was not routinely undertaken in our 
centre during this study period. Mini Mental State Examination (MMSE) (22) was completed preoperatively. Participants were not assessed for delirium preoperatively.

Postoperatively participants were assessed for delirium once daily for the first three days by trained medical research staff (TM then ELC). The MMSE, including the spelling WORLD backwards test of attention, and the Confusion Assessment Method (CAM) (23) were completed on each occasion with symptoms or signs of delirium sought from nursing staff. Delirium was deemed to be present or absent based on the CAM criteria. An additional test of attention - months of the year backwards (MOTYB) was added during the study. In addition, where possible, medical and nursing notes were interrogated post-discharge by the researchers or a research assistant. In all cases where there were reports of possible delirium but the CAM criteria had not been fulfilled, cases were discussed between ELC and APP and a consensus reached as to whether they reflected delirium according to the Diagnostic and Statistical Manual of Mental Disorders (DSM) IV criteria (24).

Both TM and ELC completed the online Confusion Assessment Method training manual and coding guide (25). TM was further trained in the use of delirium assessments by experienced research nurses. ELC was further trained and observed by TM in the delirium assessments prior to undertaking recruitment. TM recruited the first 35 participants and ELC the remaining 247, each completing the delirium assessments for those participants.

\section{Sample collection}

Venous blood was sampled preoperatively into PAXgene Blood DNA tubes (PreAnalytiX; Qiagen/BD, Catalogue No. 761125). Spinal anaesthetics were carried out in the sitting or lateral positions using 25 gauge (diameter $0.53 \mathrm{~mm}$; length $90 \mathrm{~mm}$ ) Whitacre type spinal needles with graduated metal introducers (Vygon). Once CSF was obtained, a $5 \mathrm{ml}$ syringe (BD Plastipak; BD) was attached to the spinal needle and up to $5 \mathrm{mls}$ of CSF withdrawn by the anaesthetist. The CSF was immediately transferred to a $30 \mathrm{ml}$ sterile polypropylene universal container (Unisurge). All samples were immediately put on wet ice in an insulated container. 
Sample processing

All samples were transported to the laboratory within 12 hours of collection. DNA samples were processed according to the manufacturer's instructions (TaqMan Single Nucleotide Polymorphism Genotyping Assay; Life Technologies; Catalogue No. 4351379). CSF samples were centrifuged at $4^{\circ} \mathrm{C}$ at $3000 \mathrm{rpm} / 1811 \mathrm{~g}$ for 5 minutes with no brake and $500 \mathrm{mcl}$ aliquots of the supernatant pipetted (Sarstedt, Germany, Catalogue No. 70.762 ) into $1.5 \mathrm{ml}$ polypropylene tubes (Sarstedt, Germany, Catalogue No. 72.69.001). By necessity, some aliquots were of a lower volume. All samples were stored at $-80^{\circ} \mathrm{C}$.

DNA collection and analysis

DNA was analysed using the TaqMan Single Nucleotide Polymorphism Genotyping Assay (Life Technologies; Catalogue No. 4351379) as per the manufacturer's instructions. APOE status was inferred from the genotype at each of the two alleles, rs7412 and rs429358 (26).

\section{CSF biomarker analysis}

CSF samples were transported to the Leonard Wolfson Biomarker Laboratory, University College London on dry ice. There A $\beta 42, \mathrm{~T}$-tau and P-tau were analysed by a single, trained, technician, blinded to the clinical data, using the INNOTEST $\beta$-amyloid (1-42), hTau Ag and Phospho-tau (181P) ELISA kits respectively (Fujirebio, Ghent, Belgium) run on a FLUOstar Omega BMG LABTECH instrument (chemiluminescent plate reader) according to the manufacturer's protocols. Samples were thawed at $21^{\circ} \mathrm{C}$ in an air-conditioned lab and vortexed prior to use. CSF biomarker values were determined using Omega software (version 5.10 R2) and a 4-parameter curve fit. Intra- and interassay CVs respectively were $2.0 \%$ and $3.9 \%$ for $A \beta 42,3.3 \%$ and $8.1 \%$ for T-tau and $1.6 \%$ and $5.1 \%$ for P-tau, according to International Organization for Standardisation standards (27). Longitudinal stability in the measurements is further monitored in the laboratory by participation in the Alzheimer's Association Quality Control program (28). 


\section{Statistical methods}

The study was powered to detect a difference in the risk of postoperative delirium between the $A P O E \& 4$ positive and negative groups based on an estimated APOE $\varepsilon 4$ carrier rate of $25.5 \%$ (29) and a rate of delirium in the $A P O E$ \&4-positive and $A P O E$ \&4-negative groups of $28 \%$ and $11 \%$, respectively, in an elective non-cardiac surgery population (30). It was estimated that 316 participants would be required to enable detection of significant difference, at the $5 \%$ significance level, with $90 \%$ power.

Biomarker concentrations were considered as continuous and dichotomous variables (based on published cut-offs of A $342<530 \mathrm{ng} / \mathrm{L}, \mathrm{T}$-tau $>350 \mathrm{ng} / \mathrm{L}, \mathrm{P}$-tau $>60 \mathrm{ng} / \mathrm{L}$ and $\mathrm{A} \beta 42 / \mathrm{P}$-tau $<6.5$ (31)). Both $A \beta 42 / P$-tau and t-tau/ A 342 ratios were calculated $(31,32)$. Univariate analyses of baseline characteristics and anaesthetic factors between the delirium and no delirium groups utilised t-tests (incorporating Levene's test for equality of variances), Mann-Whitney $U$ tests and chi-squared test with Yates' correction (or Fisher's exact test) as appropriate.

Where appropriate, non-normally distributed variables were logarithmically (log) transformed and analysed using t-tests. Group characteristics were presented as geometric means (with interquartile range (IQR) of raw values) where the geometric mean is the antilog of the arithmetic mean (the mean of the log transformed values).

Binary logistic regression, with postoperative delirium as the dependent variable and continuous CSF variables as the independent variables undertaken using an entry significance level of $10 \%(P<0.10)$. Analysis was performed using SPSS for Windows version 22 (IBM Inc., Armonk, NY, USA). Given the range of MMSE scores and the possibility that the cohort included participants with undiagnosed dementia the analyses were rerun in those with a preoperative MMSE $\geq 24$. Methods and results are presented in accordance with STROBE guidance (33) where possible. 


\section{Results}

Baseline characteristics of the entire cohort and the delirium and no delirium groups are outlined in Table 1. Ethnicity was not considered during recruitment but all participants were white reflecting the racial homogeneity of those presenting for surgery in our centre. Of the 315 participants recruited 282 had sufficient CSF for A $\beta 42$ and P-tau analyses with 279 of these also sufficient for Ttau analyses. The rate of delirium in the subgroup with sufficient CSF (40/282 [14\%] vs 44/315 [14\%]) was not significantly different to the cohort as a whole $(\chi 2=0.006, P=0.94)$.

The number of $A P O E \varepsilon 4$ alleles $(0,1$ or 2$)$ was not associated with postoperative delirium. Table 1 also shows the univariate analyses significant at the $10 \%$ level (and therefore entered into the logistic regression model) and these are highlighted in bold. Age, knee vs hip surgery, ASA status, CCI, MMSE, CSF A $\beta 42$, CSF T-tau and CSF P-tau showed significant differences between the delirium and no delirium groups on univariate analyses. Gender, years of education, estimated IQ, Bristol Activities of Daily Living Scale score, Geriatric Depression Scale score, smoking status and units of alcohol per week were not significantly different between the delirium and no delirium groups.

The results of the sensitivity analysis, carried out using only the 239 participants with an MMSE $\geq 24$, are also shown in Table 1. ASA status, CCI, CSF T-tau and CSF P-Tau were not significantly different between the delirium and no delirium groups for these participants.

Univariate analyses of operative and anaesthetic factors, where the information was available, are outlined for the delirium and no delirium groups in Table SDC1. Only intraoperative intravenous opioid usage was significantly different between delirium and no delirium groups, and only for the whole cohort $(p=0.039)$, this did not withstand the sensitivity analysis $(p=0.105)$. Of those 27 participants receiving intraoperative intravenous opioids, 22 received alfentanil and 5 fentanyl. Entering those variables predicting delirium in the univariate analysis into the binary logistic regression (Table 2), shows that age, $\mathrm{CCl}$, type of surgery, intravenous opioid and CSF $A \beta 42$ are 
independent predictors of postoperative delirium in the entire cohort. Thus the odds ratio of developing delirium postoperatively is increased by a factor of 1.1 for each additional year of age, 1.8 for each additional class of the $\mathrm{CCl}$ and 2.9 with the usage of intravenous opioids and decreased by a factor of 0.4 for hip vs knee surgery and 0.996 for each unit (ng/L) increase in CSF A $\beta 42$. Interaction effects were considered for these five variables and the interaction effect of $\mathrm{CCl}$ and intravenous opioids, only, was significant $(p=0.023)$. Of note the interaction effect of age and CSF A $\beta 42$ did not significantly affect the model $(p=0.388)$. This analysis was rerun in the MMSE $\geq 24$ group. Fewer variables were entered (see Table 1 for those significant at the $p=0.1$ level) but the analysis yielded similar results (Table 2). CSF $A \beta 42 / p$ tau and t tau/ CSF $A \beta 42$ ratios were too highly correlated with the individual concentrations to be included in the same model.

\section{Discussion}

This study finds CSF A 42 concentrations to be the strongest independent predictor of postoperative delirium following elective arthroplasty in an older population without a prior diagnosis of dementia. Importantly, this association was independent of tau and suggests that cerebral $\beta$-amyloidosis per se may make the brain vulnerable to postoperative delirium.

Whilst this finding is in keeping with epidemiological literature suggesting an association between dementia pathophysiology and delirium it is the first time to our knowledge that it has been demonstrated in an elective surgical population. These findings are significant as they i) provide in vivo biomarker evidence that support epidemiological and animal work suggesting a link between Alzheimer pathophysiology and delirium ii) potentially shed light on the association between delirium and subsequent cognitive decline.

Decline in CSF A 42 level is thought to be a very early feature of Alzheimer's disease, and to occur a decade or more prior to the onset of any cognitive symptoms. Deposition of $A \beta$ within the brain is thought to trigger a number of different pathophysiological processes including neuroinflammation, synaptic dysfunction, network breakdown, and neuronal loss, all of which also occur before the 
onset of symptoms. Whilst the exact mechanisms are unclear, it is likely, that individuals with presymptomatic $A D$ pathology are more vulnerable to the effects of stressors, including opiates, pain, and inflammatory changes seen in surgery (34), which may result in delirium.

Recent observational data has demonstrated an association between postoperative delirium and subsequent cognitive impairment $(35,36)$, and also between postoperative delirium and a more significant rate and magnitude of decline in cognitive function with reference to preoperative levels (37). Future work will explore whether delirium itself exerts detrimental pathophysiological effects. Studies of longer term post-operative cognitive dysfunction often do not assess for delirium in the initial postoperative days. Evered et al have demonstrated an association between preoperative CSF $A \beta 42$, but not T-tau or P-Tau, concentrations and cognitive dysfunction three months following elective hip arthroplasty (38) however it is not clear whether this association was mediated by delirium. That the effects of surgery, and anaesthesia, could possibly mediate AD pathophysiology changes has been investigated with conflicting results (39-42).

The much less significant difference in CSF T-tau between the delirium and no delirium groups in this study is perhaps unsurprising given the closer temporal association of CSF T-tau, reflecting neurodegeneration, and cognitive decline and the exclusion of patients with a diagnosis of dementia from this study. This is supported by the further weakening of the association once those participants with preoperative MMSE $\leq 24$ were excluded. CSF $A \beta 42 / p$ tau and $t$ tau/A $\beta 42$ ratios were significantly different between delirium and no delirium groups however they could not be included in the multivariable regression as they are too highly correlated with the biomarker concentration variables. Whilst ratios offer information over and above the individual biomarker concentrations it is likely, in this study, the significance is driven by the CSF A 342 results.

We are aware of only three similar studies, of which only one has been undertaken in an elective population. Xie et al showed an association between quartiles of CSF A $\beta /$ tau ratios and delirium but no association between individual biomarker concentrations. Of note their CSF analyses were 
conducted outwith the Alzheimer's Association Quality Control program (28) and they reported relatively high intra-assay CVs $(21.8,18.7$ and 6.8\%) (10). Of the two studies conducted in hip fracture populations, the findings of Idland et al contradicted Witlox et al by demonstrating an association between CSF A 442 and tau in a non-demented population $(12,13)$. Like us Idland et al analysed samples in an expert laboratory however hip fracture and elective orthopaedic populations vary significantly in age, comorbidity and baseline functional ability as well as circumstances precipitating delirium $(3,43)$ and so whilst these studies are relevant the populations should be considered independently.

$\mathrm{CCl}$ scores in this study were largely reliant on diabetes and vascular disease. This ties in with these AD pathophysiological processes but more work is needed to further elicit these associations.

It is not clear why delirium should be more common following knee rather than hip arthroplasty, the greater pain, and by extension analgesic burdens, seen following knee compared to hip surgery may be contributory. In addition, the utilisation of a tourniquet during total knee replacement, as was common practice for this cohort, could increase neuroinflammatory burden via the washout of an ischaemic limb. Further work is needed.

All participants in this study received intrathecal diamorphine. The independent association between additional intraoperative intravenous opioid administration and postoperative delirium is in keeping with broader published evidence associating opioids and delirium in hospitalised patients (44) however studies examining intraoperative intravenous opioids are limited (45). The numbers of participants receiving fentanyl in our study are too small to challenge recent findings suggesting it is a safer opioid however the relatively high numbers receiving alfentanil, and the limited evidence base available assessing delirium risk in elderly elective surgical populations require further study. That the association does not withstand our sensitivity analysis suggests patients with established cognitive impairment are the most vulnerable, which supports existing guidelines advocating an individualised, opioid-sparing anaesthetic approach in the elderly (46). The significant interaction 
effect of $\mathrm{CCl}$ and intravenous opioid raises the possibility opioids were preferred for those frailer more comorbid participants, or that opioids carried an additive delirium risk for these participants. Further research is needed. It is important to note that this study was not powered to examine for anaesthetic factors as predictors of delirium.

Given that $A P O E \& 4$ is a strong risk factor for AD through reduction of CSF AB42 (47) it is perhaps surprising that the rate of $\varepsilon 4$ positivity was similar, and not significantly different, between the two groups ( $28 \%$ vs $25 \%$ ). Further studies are required to replicate this, and also to assess for the other genetic risk factors for sporadic AD.

This study has a number of strengths, including the relatively large sample size, the prospective ascertainment of delirium via daily assessment by a trained researcher utilising a recognised tool, supplemented by notes review, and high accuracy of CSF measurements, as reflected by the very low CVs, conducted in a centre of excellence. Potential limitations to the study include the possible inclusion of patients with undiagnosed dementia, although our sensitivity analyses using the standard MMSE $\geq 24$ cut-off goes a way towards addressing this concern. Patients must be well to undergo elective surgery. Any evidence of intercurrent illness would mandate cancelling of surgery in our unit therefore it is unlikely participants would have been delirious preoperatively however the absence of explicit preoperative screening for delirium is a limitation of this study. Correction was not made for the multiple univariable comparisons, thereby increasing the risk of a type 1 error, although a multivariable regression model was subsequently utilised.

\section{Conclusions}

Postoperative delirium is common and is associated with subsequent cognitive impairment, functional decline and death. This study is the first to show an independent association between CSF $A \beta 42$ and delirium and in so doing informs the evolving understanding of delirium pathophysiology and raises the possibility that delirium is indicative of an underlying $A D$ process. Further work is required to understand this potential relationship in more detail, and how it interacts with vascular 
risk, using CSF measures of inflammation, and structural and molecular brain imaging. Long term cognitive follow-up is needed to determine if, as predicted, postoperative delirium is a marker for the subsequent development of Alzheimer's disease: if so this has implications for ongoing follow-up and management of these patients and in due course may provide a means of identifying high risk individuals who will benefit from disease modifying therapies as/when they become available.

\section{Acknowledgements}

Many people contributed to the successful completion of this study. In particular we gratefully acknowledge the support of the Leonard Wolfson Experimental Neurology Centre, especially Dr Amanda Heslegrave and Ms Elizabeth Halton and the Dementia Research Centre in UCL, especially Professor Nick Fox; the Cheung family for support via the Siew Keok Chin scholarship; the Belfast Arthroplasty Research Trust; Belfast Trust Charitable Funds; the anaesthetists, surgeons, theatre and ward staff of Musgrave Park Hospital; Mr John Conlon of the Centre for Experimental Medicine, QUB for technical laboratory support; Professor Chris Patterson of the Centre for Public Health for statistical support; Dr Rebecca Cairns and Ms Lauren Anderson for data inputting; Mrs Hazel Johnston and Mrs Eilish Armstrong for neuropsychology training.

\section{References}

1. Scott JE, Mathias JL, Kneebone AC. Incidence of delirium following total joint replacement in older adults: a meta-analysis. Gen Hosp Psychiatry. 2015 May-Jun;37(3):223-9.

2. Inouye SK, Westendorp RG, Saczynski JS. Delirium in elderly people. The Lancet. 2014 3/814;383(9920):911-22.

3. The NJR Editorial Board. 12th Annual Report 2015: National Joint Registry for England, Wales, Northern Ireland and the Isle of Man. Hemel Hempstead: National Joint Registry; 2015. Report No.: 12.

4. Dasgupta M, Dumbrell AC. Preoperative risk assessment for delirium after noncardiac surgery: a systematic review. J Am Geriatr Soc. 2006 Oct;54(10):1578-89.

5. van Meenen LC, van Meenen DM, de Rooij SE, ter Riet G. Risk prediction models for postoperative delirium: a systematic review and meta-analysis. J Am Geriatr Soc. 2014 Dec;62(12):2383-90. 
6. van Munster BC, Korevaar JC, Zwinderman AH, Leeflang MM, de Rooij SE. The association between delirium and the apolipoprotein E epsilon 4 allele: new study results and a meta-analysis. Am J Geriatr Psychiatry. 2009 Oct;17(10):856-62.

7. Abelha FJ, Fernandes V, Botelho M, Santos P, Santos A, Machado JC, et al. Apolipoprotein E e4 allele does not increase the risk of early postoperative delirium after major surgery. J Anesth. 2012 Feb 1.

8. Vasunilashorn SM, Ngo L, Kosar CM, Fong TG, Jones RN, Inouye SK, et al. Does Apolipoprotein E Genotype Increase Risk of Postoperative Delirium? Am J Geriatr Psychiatry. 2015 May 21.

9. Olsson B, Lautner R, Andreasson U, Öhrfelt A, Portelius E, Bjerke M, et al. CSF and blood biomarkers for the diagnosis of Alzheimer's disease: a systematic review and meta-analysis. The Lancet Neurology. 2016 6;15(7):673-84.

10. Xie Z, Swain CA, Ward SA, Zheng H, Dong Y, Sunder N, et al. Preoperative cerebrospinal fluid beta-Amyloid/Tau ratio and postoperative delirium. Ann Clin Transl Neurol. 2014 May 1;1(5):319-28.

11. Hirsch J, Vacas S, Terrando N, Yuan M, Sands LP, Kramer J, et al. Perioperative cerebrospinal fluid and plasma inflammatory markers after orthopedic surgery. J Neuroinflammation. 2016 Aug 30;13(1):211,016-0681-9.

12. Witlox J, Kalisvaart KJ, de Jonghe JF, Verwey NA, van Stijn MF, Houdijk AP, et al. Cerebrospinal fluid beta-amyloid and tau are not associated with risk of delirium: a prospective cohort study in older adults with hip fracture. J Am Geriatr Soc. 2011 Jul;59(7):1260-7.

13. Idland AV, Wyller TB, Stoen R, Eri LM, Frihagen F, Raeder J, et al. Preclinical Amyloid-beta and Axonal Degeneration Pathology in Delirium. J Alzheimers Dis. 2016 Sep 20.

14. ASA Physical Status Classification System [Internet]. []. Available from: https://www.asahq.org/resources/clinical-information/asa-physical-status-classification-system.

15. Charlson ME, Pompei P, Ales KL, MacKenzie CR. A new method of classifying prognostic comorbidity in longitudinal studies: development and validation. J Chronic Dis. 1987;40(5):373-83.

16. Nelson HE, Willison J. The National Adult Reading Test (NART). 1991.

17. Bucks RS, Ashworth DL, Wilcock GK, Siegfried K. Assessment of activities of daily living in dementia: development of the Bristol Activities of Daily Living Scale. Age Ageing. 1996 Mar;25(2):113-20.

18. Yesavage JA, Brink TL, Rose TL, Lum O, Huang V, Adey M, et al. Development and validation of a geriatric depression screening scale: a preliminary report. J Psychiatr Res. 1982 -1983;17(1):37-49.

19. Raats JW, Steunenberg SL, de Lange DC, van der Laan L. Risk factors of post-operative delirium after elective vascular surgery in the elderly: A systematic review. Int J Surg. 2016 Nov;35:1-6.

20. Shi C, Yang C, Gao R, Yuan W. Risk Factors for Delirium After Spinal Surgery: A Meta-Analysis. World Neurosurg. 2015 Jun 17. 
21. Scholz AF, Oldroyd C, McCarthy K, Quinn TJ, Hewitt J. Systematic review and meta-analysis of risk factors for postoperative delirium among older patients undergoing gastrointestinal surgery. $\mathrm{Br} \mathrm{J}$ Surg. 2016 Jan;103(2):e21-8.

22. Folstein MF, Folstein SE, McHugh PR. "Mini-mental state". A practical method for grading the cognitive state of patients for the clinician. J Psychiatr Res. 1975 Nov;12(3):189-98.

23. Inouye SK, van Dyck CH, Alessi CA, Balkin S, Siegal AP, Horwitz RI. Clarifying confusion: the confusion assessment method. A new method for detection of delirium. Ann Intern Med. 1990 Dec $15 ; 113(12): 941-8$.

24. American Psychiatric Association. Diagnostic and statistical manual of mental disorders. Washington, DC: American Psychiatric Association; 2000. Report No.: 4th Edition.

25. Inouye SK. The Confusion Assessment Method (CAM): Training Manual and Coding Guide. 2003.

26. Belbin O, Dunn JL, Ling Y, Morgan L, Chappell S, Beaumont $\mathrm{H}$, et al. Regulatory region single nucleotide polymorphisms of the apolipoprotein $E$ gene and the rate of cognitive decline in Alzheimer's disease. Hum Mol Genet. 2007 Sep 15;16(18):2199-208.

27. International Organization for Standardization. Accuracy (trueness and precision) of measurement methods and results -- Part 2: Basic method for the determination of repeatability and reproducibility of a standard measurement method. . British Standards Institution; 1994. Report No.: ISO 5725-1.

28. Mattsson N, Andreasson U, Persson S, Carrillo MC, Collins S, Chalbot S, et al. CSF biomarker variability in the Alzheimer's Association quality control program. Alzheimers Dement. 2013 May;9(3):251-61.

29. McKay GJ, Silvestri G, Chakravarthy U, Dasari S, Fritsche LG, Weber BH, et al. Variations in apolipoprotein $E$ frequency with age in a pooled analysis of a large group of older people. Am J Epidemiol. 2011 Jun 15;173(12):1357-64.

30. Leung JM, Sands LP, Wang Y, Poon A, Kwok PY, Kane JP, et al. Apolipoprotein E e4 allele increases the risk of early postoperative delirium in older patients undergoing noncardiac surgery. Anesthesiology. 2007 Sep;107(3):406-11.

31. Hansson O, Zetterberg H, Buchhave P, Londos E, Blennow K, Minthon L. Association between CSF biomarkers and incipient Alzheimer's disease in patients with mild cognitive impairment: a follow-up study. Lancet Neurol. 2006;5:228-34.

32. Shaw LM, Vanderstichele H, Knapik-Czajka M, Clark CM, Aisen PS, Petersen RC, et al. Cerebrospinal fluid biomarker signature in Alzheimer's disease neuroimaging initiative subjects. Ann Neurol. 2009 Apr;65(4):403-13.

33. von Elm E, Altman DG, Egger M, Pocock SJ, Gotzsche PC, Vandenbroucke JP, et al. The Strengthening the Reporting of Observational Studies in Epidemiology (STROBE) statement: guidelines for reporting observational studies. J Clin Epidemiol. 2008 Apr;61(4):344-9.

34. Berger M, Burke J, Eckenhoff R, Mathew J. Alzheimer's disease, anesthesia, and surgery: a clinically focused review. J Cardiothorac Vasc Anesth. 2014 Dec;28(6):1609-23. 
35. Saczynski JS, Marcantonio ER, Quach L, Fong TG, Gross A, Inouye SK, et al. Cognitive trajectories after postoperative delirium. N Engl J Med. 2012 Jul 5;367(1):30-9.

36. Sprung J, Roberts RO, Weingarten TN, Nunes Cavalcante A, Knopman DS, Petersen RC, et al. Postoperative delirium in elderly patients is associated with subsequent cognitive impairment. $\mathrm{Br} J$ Anaesth. 2017 Aug 1;119(2):316-23.

37. Inouye SK, Marcantonio ER, Kosar CM, Tommet D, Schmitt EM, Travison TG, et al. The short-term and long-term relationship between delirium and cognitive trajectory in older surgical patients. Alzheimers Dement. 2016 Jul;12(7):766-75.

38. Evered L, Silbert B, Scott DA, Ames D, Maruff P, Blennow K. Cerebrospinal Fluid Biomarker for Alzheimer Disease Predicts Postoperative Cognitive Dysfunction. Anesthesiology. 2016 Feb;124(2):353-61.

39. Tang JX, Baranov D, Hammond M, Shaw LM, Eckenhoff MF, Eckenhoff RG. Human Alzheimer and inflammation biomarkers after anesthesia and surgery. Anesthesiology. 2011 Oct;115(4):727-32.

40. Zhang $B$, Tian $M$, Zheng $H$, Zhen $Y$, Yue $Y$, Li T, et al. Effects of anesthetic isoflurane and desflurane on human cerebrospinal fluid Abeta and tau level. Anesthesiology. 2013 Jul;119(1):52-60.

41. Anckarsater R, Anckarsater H, Bromander S, Blennow K, Wass C, Zetterberg H. Non-neurological surgery and cerebrospinal fluid biomarkers for neuronal and astroglial integrity. J Neural Transm (Vienna). 2014 Jun;121(6):649-53.

42. Berger M, Nadler JW, Friedman A, McDonagh DL, Bennett ER, Cooter M, et al. The Effect of Propofol Versus Isoflurane Anesthesia on Human Cerebrospinal Fluid Markers of Alzheimer's Disease: Results of a Randomized Trial. J Alzheimers Dis. 2016 Apr 15;52(4):1299-310.

43. National Hip Fracture Database. National Hip Fracture Database (NHFD) annual report 2015. London: Royal College of Physicians; 2015.

44. Clegg A, Young JB. Which medications to avoid in people at risk of delirium: a systematic review. Age Ageing. 2011 Jan;40(1):23-9.

45. Swart LM, van der Zanden V, Spies PE, de Rooij SE, van Munster BC. The Comparative Risk of Delirium with Different Opioids: A Systematic Review. Drugs Aging. 2017 Jun;34(6):437-43.

46. Griffiths R, Beech F, Brown A, Dhesi J, Foo I, Goodall J, et al. Peri-operative care of the elderly 2014: Association of Anaesthetists of Great Britain and Ireland. Anaesthesia. 2014 Jan;69 Suppl 1:8198.

47. Andreasson U, Lautner R, Schott JM, Mattsson N, Hansson O, Herukka SK, et al. CSF biomarkers for Alzheimer's pathology and the effect size of APOE varepsilon4. Mol Psychiatry. 2014 Feb;19(2):148-9. 